\title{
Global climatological variability of quasi-two-day waves revealed by TIMED/SABER observations
}

\author{
Y. Y. Huang, S. D. Zhang, F. Yi, C. M. Huang, K. M. Huang, Q. Gan, and Y. Gong \\ School of Electronic Information, Wuhan University, Wuhan, Hubei, China \\ Key Laboratory of Geospace Environment and Geodesy, Ministry of Education, Wuhan, Hubei, China \\ State Observatory for Atmospheric Remote Sensing, Wuhan, Hubei, China \\ Correspondence to: S. D. Zhang (zsd@whu.edu.cn)
}

Received: 31 December 2012 - Revised: 9 May 2013 - Accepted: 14 May 2013 - Published: 14 June 2013

\begin{abstract}
This paper presents characteristics of quasi-twoday waves (QTDWs) in the mesosphere and lower thermosphere (MLT) between $52^{\circ} \mathrm{S}$ and $52^{\circ} \mathrm{N}$ from 2002 to 2011 using TIMED/SABER temperature data. Spectral analysis suggests that dominant QTDW components at mid-high latitudes of the Southern Hemisphere (SH) and the Northern Hemisphere (NH) are (2.13, W3) and (2.04, W4), respectively. The most remarkable QTDW is $(2.13$, W3), which happened in the southern summer of 2002-2003 at $32^{\circ} \mathrm{S}$ from 60 to $90 \mathrm{~km}$ in altitude. Its downward phase propagation indicates upward propagation of the wave energy and a potential source region below $60 \mathrm{~km}$. Analysis of horizontal wind fields in the same period shows the westward and southward propagation of $(2.13, \mathrm{~W} 3)$ and a possible reflection region above $90 \mathrm{~km}$. Fundamental parameters of QTDWs present significant interhemispheric differences and interannual variations in statistical analysis. Amplitudes in the SH are twice larger than that in the $\mathrm{NH}$, and vertical wavelengths are a little longer in the SH. QTDWs may endure stronger dissipation in southern summer because of shorter durations of their attenuation stages. Impact of the equatorial quasibiennial-oscillation (QBO) on QTDWs can extend to midhigh latitudes of both hemispheres. It seems easier for QTDWs to propagate upward in the equatorial QBO's westerly phase in the lower stratosphere and easterly phase in the middle stratosphere. Interannual variations of QTDW strength may be influenced by solar activity as well. Strengths of QTDWs appear to be stronger (weaker) in the solar maximum (minimum).
\end{abstract}

Keywords. Meteorology and atmospheric dynamics (middle atmosphere dynamics)

\section{Introduction}

Planetary waves (PWs) are common atmospheric waves mainly excited by uneven heating of the atmosphere and zonally asymmetric distribution of topography (Charney and Drazin, 1961; Salby, 1984). Primary periods of the PWs contain quasi-two-day, quasi-five-day, quasi-ten-day and quasisixteen-day waves(Jacobi et al., 1998; Wang et al., 2010). The most prominent component in the MLT is the quasitwo-day wave (QTDW), which is able to affect horizontal wind and temperature in the middle atmosphere (Palo et al., 1999). Amplitudes of QTDWs in temperature and wind can reach $12 \mathrm{~K}$ (Tunbridge et al., 2011) and $60 \mathrm{~m} \mathrm{~s}^{-1}$ (Wu et al., 1993). Traces of QTDWs can also be found in atmospheric $\mathrm{H}_{2} \mathrm{O}$, carbon monoxide, $\mathrm{OH}$ emission, and height of the $\mathrm{F} 2$ layer (Wu et al., 1993; Randel, 1994; Forbes and Zhang, 1997; Limpasuvan and Wu, 2003; Limpasuvan et al., 2005; Tunbridge et al., 2011; Pedatella and Forbes, 2012). Moreover, QTDWs are found to be important in photochemical processes in the mesopause region (Kulikov, 2007). Many studies have suggested that QTDWs can frequently interact with solar tides (Palo et al., 1999; Salby and Callaghan, 2008; McCormack et al., 2010; Babu et al., 2011; Forbes and Moudden, 2012), other PWs (Babu et al., 2011) and gravity waves (GWs) (Palo et al., 1999). Interactions between QTDWs and migrating tides are proved to be a major mechanism in the generation of non-migrating tides (Palo et al., 1999; Pedatella and Forbes, 2012). When the sudden stratospheric 
warming (SSW) occurs, background zonal wind changes and the QTDW forcing in both the tropical and extratropical regions may be influenced (McCormack et al., 2009; Lima et al., 2012). Recently, research has reported that QTDWs can be modulated by low-frequency oscillations of the atmosphere, such as the quasi-biennial oscillation (QBO) in equatorial zonal wind (Li et al., 2008) and solar activities (Jacobi et al., 1997), and yield interannual variations of QTDWs. All of these studies indicated that QTDWs have close relationships with many important dynamical processes in the middle and upper atmosphere. Therefore, intensive studies of QTDW characteristics are needed.

Primary characteristics of QTDWs are revealed from ground-based observations in recent decades. QTDWs are transient and intermittent wave phenomenon. Usually, they happen after summer solstice in the middle and upper atmospheres and last for several weeks, about 13-15 wave periods (Meek et al., 1996; Pancheva et al., 2004). In the northern summer, they perform series of burst events separated for 5-8 days (Riggin et al., 2004; Dutta et al., 2012). Their peak amplitudes often occur at $70 \mathrm{~km}$ (Malinga and Ruohoniemi, 2007), and they also exist in the lower atmosphere at low latitude (Dutta et al., 2012). Vertical wavelengths of them range from 40 to $110 \mathrm{~km}$ (Pancheva et al., 2004). In the Southern Hemisphere (SH), their periods and wavenumbers are about $48 \mathrm{~h}$ and -3 (minus means westward propagation), respectively, while in the Northern Hemisphere $(\mathrm{NH})$, periods contain 53-56, 48-50 and 42-43 h, with corresponding wavenumbers $-2,-3$ and -4 (Craig et al., 1980; Pancheva et al., 2004; Malinga and Ruohoniemi, 2007). Moreover, numerous observations have verified the nonlinear interactions between QTDWs and other PWs (Pancheva et al., 2004; Babu et al., 2011; Li and Ning, 2011), which can partly explain the short-term variations of QTDWs. However, background atmospheric wind fields can also impact QTDW dayto-day variations. In addition, Jacobi et al. (1997) found that solar activity can possibly impact interannual variations of QTDWs. During the solar maximum, amplitudes of QTDWs are larger at high latitudes in the $\mathrm{NH}$.

Although great achievements have been attained, it is difficult to comprehensively understand global propagation of QTDWs only from these ground-based observations, which are generally scattered geographically. Satellites can almost provide whole global wind fields, temperature and atmospheric compositions from the upper troposphere to the lower thermosphere. For example, the Constellation $\mathrm{Ob}-$ serving System for Meteorology, Ionosphere, and Climate (COSMIC) can measure the lower atmospheric temperature (He et al., 2009; Yang and Zou, 2012); the Upper Atmospheric Research Satellite/High Resolution Doppler Imager (UARS/HRDI) measures temperature, zonal and meridional wind, water vapor and ozone concentration in the middle and upper atmosphere (Wu et al., 1993, 1996); the Thermosphere Ionosphere Mesosphere Energetics Dynamics/Sounding of the Atmosphere using Broadband Emission
Radiometry (TIMED/SABER) is used for temperature measurements in the upper atmosphere (Xu et al., 2007a, b); and the line-of-sight (LOS) winds can be surveyed by the Microwave Limb Sounder (MLS) on Aura (Tunbridge et al., 2011). Satellite observations contribute greatly to our knowledge of global morphology of QTDWs. Evident QTDWs often occur in the middle and upper atmosphere at mid-high latitudes after summer solstice (Rodger and Prata, 1981; Randel, 1994; Tunbridge et al., 2011), and amplitudes of them are twice larger in the SH than in the NH (Limpasuvan et al., 2000). Wavenumbers of distinctive QTDWs in the SH are usually -3 , while in the NH they are -3 and -4 (Limpasuvan et al., 2000; Garcia et al., 2005). Different wavenumbers may result from different strength of easterlies. Weaker easterlies tend to maintain wave with wavenumber -4 (Limpasuvan et al., 2000). Several dynamical processes may be associated with QTDWs as well. Wu et al. (1996) indicated that QTDWs in the summer hemisphere may be related to the propagation of PWs in the winter hemisphere. Moreover, nonlinear interactions between QTDWs and other waves can probably lead to short-term variations of QTDWs (Hecht et al., 2010; McCormack et al., 2010). Furthermore, modulation of long-term dynamics, e.g. QBO, on QTDWs may result in their interannual variations (Li et al., 2008). However, mechanisms of these variations have not been clearly understood.

SABER, onboard the TIMED satellite, measures neutral temperature from the stratosphere to the lower thermosphere with high vertical resolution and precision (Xu et al., 2006; Remsberg et al., 2008). Therefore, it has been widely applied in studies of atmospheric structures (Xu et al., 2007a, b; Dou et al., 2009; Gan et al., 2012), GWs (Preusse et al., 2006; John and Kumar, 2012), tides (Zhang et al., 2006; Pancheva et al., 2009; Xu et al., 2009) and PWs (John and Kumar, 2011). Garcia et al. (2005) and $\mathrm{Li}$ et al. (2008) also studied QTDWs based on SABER observations. Li et al. (2008) have studied the QTDWs using SABER data. Nevertheless, only data during 2002-2004 are utilized and only QTDWs in the NH are of concern in this study. Therefore, it is necessary to study the global climatologic features of QTDWs using SABER observations.

In this paper, we investigate the global climatology of QTDWs by TIMED/SABER temperature data from 2002 to 2011 between 30 and $100 \mathrm{~km}$ in height and between $52^{\circ} \mathrm{S}$ and $52^{\circ} \mathrm{N}$ in latitude. In combination with the refractive index, impact of background wind fields on short-term variations of QTDWs is studied. Interannual variations of QTDWs are presented and their possible causes are discussed. In Sect. 2, data employed in this paper are introduced. In Sect. 3, temperature data from TIMED/SABER are spectrally analyzed, and latitude-altitude distributions of the dominant QTDW amplitudes are presented. A detailed investigation of short-term variations of the strongest QTDW event at $32^{\circ} \mathrm{S}$ in the southern summer from 2002 to 2003 is depicted in Sect. 4, and UARS/HRDI wind data are also used in analyzing the impacts of background horizontal wind fields. 
Interannual variations and statistical analysis of QTDWs are described in Sect. 5. Conclusions are given in Sect. 6.

\section{Observations and data analysis}

\subsection{SABER temperature data}

TIMED was launched from Vandenberg Air Force Base on 7 December 2001, and began to record data on 25 January 2002. SABER, onboard TIMED, uses limb-scanning, broadband infrared radiometry to survey the energetics, chemistry, dynamics and mass transportations over a broad range of altitude from the upper troposphere to the lower thermosphere (Russell III et al., 1999). As a polar-orbiting satellite, TIMED makes about 15 orbits per day in a $625 \mathrm{~km}$ and $74^{\circ}$ inclination orbit, with respective resolutions of altitude and latitude about $2 \mathrm{~km}$ and $4^{\circ}$. About every 60 days, the latitude ranges flip as the spacecraft yaws to keep the instrument on the anti-sun side of the spacecraft. Latitude coverage on a given day extends from about $52^{\circ} \mathrm{S}(\mathrm{N})$ to $83^{\circ} \mathrm{N}$ (S); however, this paper does not generate results greater than $52^{\circ}$. If taking ascending and descending data together, the TIMED takes 60 days to cover $24 \mathrm{~h}$ in local time. SABER temperature data of version 1.07 from 2002 to 2011 are used in this paper, and altitude resolution is interpolated into $1 \mathrm{~km}$.

\subsection{HRDI horizontal wind data}

A case of $(2.13, \mathrm{~W} 3)$, which occurred in $32^{\circ} \pm 2^{\circ} \mathrm{S}$ latitude band in the southern summer from December 2002 to February 2003, is studied in order to investigate short-term variations of QTDW parameters and reasons why they varied. Wind data are needed in order to search for the impact of background wind fields. Although balanced winds can be calculated using SABER measurements as well, some smallscale structures cannot be shown in the balanced wind (figure not shown here), which may have resulted from the hypothesis and inversion method in calculating the balanced wind. Considering this, horizontal winds observed by UARS/HRDI are utilized in this case study.

UARS was launched on 12 September 1991. The spacecraft is in a $57^{\circ}$ inclination, approximately circular orbit, with an altitude of $585 \mathrm{~km}$. HRDI, onboard the UARS, commenced continuous geophysical observations on 6 November of the same year. It employs a triple-etalon Fabry-Perot interferometer to measure the Doppler shift of rotational lines in the $\mathrm{O}_{2}$ atmospheric band. During daytime, MLT wind fields are obtained in the altitude range extended from 50 to $115 \mathrm{~km}$ with $2.5 \mathrm{~km}$ resolution, while during nighttime the observed emission is confined to a narrow layer, restricting measurements to a single altitude of about $95 \mathrm{~km}$ (Hays et al., 1993). As a result, only daytime measurements are available at nearly all altitudes except around $95 \mathrm{~km}$. If both ascending and descending points are taken into consideration,
HRDI takes 36 days to cover $24 \mathrm{~h}$ in local time (Reber et al., 1993; Burrage et al., 1996).

\subsection{NCEP/NCAR reanalysis data}

The National Center for Environmental Prediction (NCEP, formerly known as the National Meteorological Center, NMC)/National Center for Atmospheric Research (NCAR) Reanalysis Project began in 1991 as an outgrowth of the NMC Climate Data Assimilation System (CDAS) project (Kalnay et al., 1996). It covers the period from January 1948 to the present and assembles a very comprehensive observational database (Kistler et al., 2001). The data assimilation is gridded into a $2.5^{\circ} \times 2.5^{\circ}$ horizontal bin (about $210 \mathrm{~km}$ horizontal resolution) with 28 vertical pressure levels. In this paper, monthly zonal mean of the zonal wind at the equator (from $5^{\circ} \mathrm{S}$ to $5^{\circ} \mathrm{N}$ ) for years $2002-2011$ of reanalysis from $100 \mathrm{hPa}$ to $10 \mathrm{hPa}$, i.e. about $16-30 \mathrm{~km}$, is used in order to compare the interannual variations of mesospheric QTDWs in temperature and the stratospheric QBO in zonal wind.

\section{QTDWs in the mesosphere}

\subsection{Spectral analysis}

According to these fundamental characteristics of SABER, special data-processing methods are used to extract disturbances and analyze characteristics of QTDWs. We first divide latitudes between $52^{\circ} \mathrm{S}$ and $52^{\circ} \mathrm{N}$ into 25 latitude bands with $4^{\circ}$ interval, and nominate each latitude band as its middle latitude. Components of PWs are determined via a spectral method introduced by Salby (1982a, b), which was considered to be suitable for asynoptic satellite sampling and has been widely used in previous studies (Lieberman, 1999; Garcia et al., 2005; Merzlyakov and Pancheva, 2007). Periods of PWs are usually between 2 and 30 days (Vincent, 1990). A PW event usually lasts several periods, and always exhibits seasonality and discontinuity (Vincent, 1984; Wang et al., 2010). Therefore, the window for spectral analysis is set to be 30 days. During summertime, the QTDW was proved to be the strongest PW in the MLT (Muller, 1972; Roger and Prata, 1981; Wu et al., 1993; Harris and Vincent, 1993; Harris, 1994; Garcia et al., 2005; Palo et al., 2007; McCormack et al., 2009), and thus it is taken as the primary topic of this paper. In addition, most of our attention is paid to the summertime in the altitude range from 70 to $90 \mathrm{~km}$ and from $30^{\circ} \mathrm{S}(\mathrm{N})$ to $50^{\circ} \mathrm{S}(\mathrm{N})$ in latitude, where intense QTDWs recur regularly (Muller, 1972; Muller and Nelson, 1978; Craig et al., 1980; Salby, 1981; Meek et al., 1996; Garcia et al., 2005; Tunbridge et al., 2011). On the satellite's yawing days, data points are extraordinarily scattered in latitude and unsuitable for spectral analysis. Therefore, we set the time window from the 350th day of one year to the 14th day of the next year in the SH and from the 161st to the 190th day of one year in the $\mathrm{NH}$ in order to avoid these days. Considering 

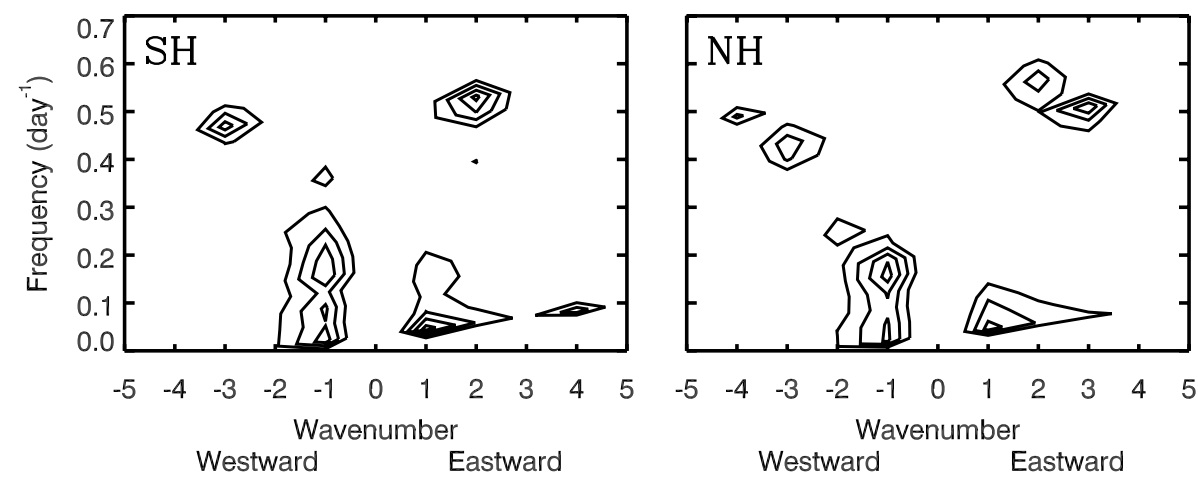

Fig. 1. The normalized mean frequency-wavenumber spectra of the temperature disturbances for different hemisphere. The minimum and interval of the contours are 0.65 and 0.1 , respectively.

that SABER takes 60 days to cover $24 \mathrm{~h}$ of local time at each latitude band, we take the average temperature of 60 days by centering on the spectral window as background temperature. Initial disturbance profiles are obtained through subtracting background temperature from raw profiles. Besides PWs, other atmospheric waves, especially diurnal migrating tides, may be superposed in the initial disturbance profiles in these periods and latitude ranges (Zhang et al., 2006), and they should be removed as much as possible before the procession of spectral analysis for PW features. We divide initial disturbance profiles of each day into two groups according to the ascending or descending orbit. Daily average initial disturbance profile of each group is subtracted from each initial disturbance profiles, and migrating tides are eliminated from disturbances. Residual disturbance profiles contain PWs, together with ignorable nonmigrating tides and GWs, and are spectrally analyzed at each altitude and latitude band, respectively. Each resultant spectrum is normalized first, and then all normalized spectra in the $\mathrm{NH}$ and $\mathrm{SH}$ are linearly averaged, respectively. For each year, 105 spectra are obtained in each hemisphere. And in total, there are 840 spectra in the $\mathrm{SH}$ and 945 spectra in the NH, respectively. Finally, the averaged spectra are normalized again. The relative power of PWs is shown in Fig. 1.

Figure 1 showed normalized mean frequencywavenumber spectra of residual disturbances in summers from 2002 to 2010 from $30^{\circ} \mathrm{S} / \mathrm{N}$ to $50^{\circ} \mathrm{S} / \mathrm{N}$ in latitude and from 70 to $90 \mathrm{~km}$ in altitude for both hemispheres. Positive (negative) wavenumber indicates eastward (westward) propagation. QTDWs are evident in both hemispheres, with periods ranging from 1.77 to 2.30 days. Double-QTDW peaks, (1.88 days, E2) ("days" is omitted hereinafter; "E" and "W" mean eastward and westward.) and (2.13, W3), exist in the SH (Fig. 1, left). Both periods and wavenumbers of these components coincide with previous observations (Limpasuvan and Leovy, 1995; Garcia et al., 2005; McCormack et al., 2009). Period and wavenumber of the westward wave are respectively longer and larger than those of the eastward wave (Garcia et al., 2005). Besides
QTDWs, quasi-five-day waves, (6.41, W1) and (6.76, E1), and quasi-ten-day waves, (11.90, E4), (12.50, E1) and $(11.24, \mathrm{~W} 1)$, are also obvious in the SH. In the NH (Fig. 1, right), more QTDW components exist, which indicates more complicated dynamics in the $\mathrm{NH}$. Wavenumbers of these are E3, E2, W3 and W4, and their corresponding periods are 1.96, 1.77, 2.30 and 2.04 days. Muller (1972) observed a QTDW of a period equaling $51 \mathrm{~h}$ (2.1 days) at mid-high latitude in the $\mathrm{NH}$, which coincide with our analysis results. Likewise, in the SH, westward QTDWs have longer periods than eastward QTDWs. Quasi-five-day wave components are different in both hemispheres. (4.08, W2) is distinctive in the $\mathrm{NH}$, while $(6.76, \mathrm{E} 1)$ only exists in the SH. For quasi-ten-day waves, $(11.90, \mathrm{E} 4)$ is absent in the $\mathrm{NH}$, but $(12.50, \mathrm{E} 1)$ and $(11.24, \mathrm{~W} 1)$ are the same as those in the SH. In conclusion, components of quasi-five-day and quasi-ten-day waves in both hemispheres are fundamentally alike, but more QTDWs exist in the NH. Thus, the environment of the middle and upper atmosphere at mid-high latitude in the summertime of the $\mathrm{NH}$ is most likely to maintain more-complicated atmospheric dynamics than the SH. More importantly, the QTDW is confirmed to be one of the most dominant atmospheric PWs in the $9 \mathrm{yr}$ averaged spectra of summers in the middle and upper atmosphere at the mid-high latitudes, and several QTDW components usually exist simultaneously. Their period range is about 1.77-2.30 days, and wavenumbers include E3, E2, W3 and W4. Moreover, more QTDWs components are found in the $\mathrm{NH}$, indicating more complicated dynamics in the $\mathrm{NH}$ and interhemispheric differences. This paper will focus on the spatial distributions of those QTDWs in both hemispheres, together with their short-term and interannual temporal variations.

\subsection{Latitude-altitude distributions of amplitudes}

In order to better understand the generation mechanisms and propagation characteristics of QTDWs, global structure of QTDW amplitudes from stratosphere to the upper 

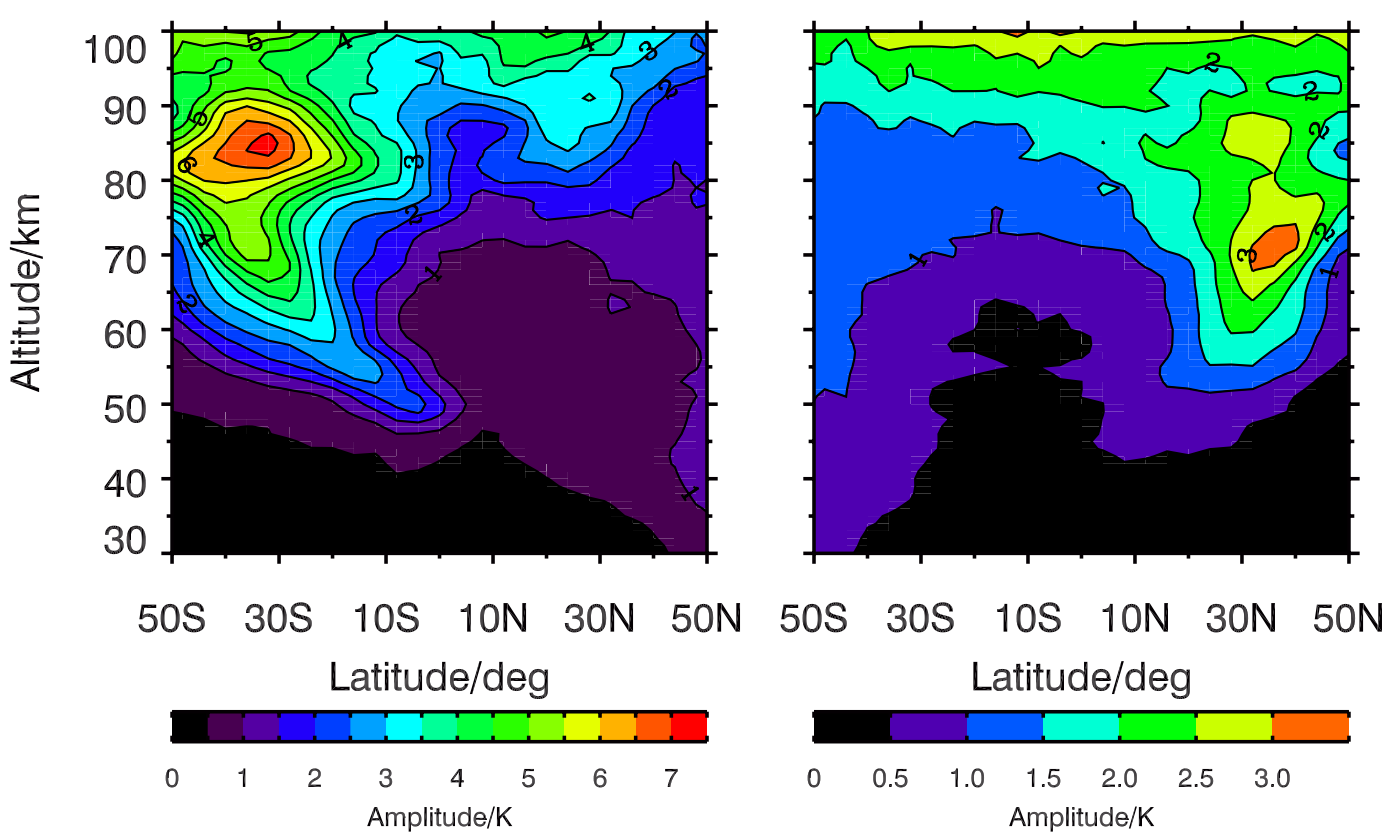

Fig. 2. Latitude-altitude distributions of averaged amplitudes of (2.13, W3) (left) and (2.04, W4) (right) for years $2002-2010$.

atmosphere from $50^{\circ} \mathrm{S}$ to $50^{\circ} \mathrm{N}$ should be figured out. For time series of residual temperature disturbances $f(t, s)$ from 2002 to 2011 at each altitude and in each latitude band, amplitudes and phases of QTDWs are harmonically fitted with a 6-day window and 1-day step. The harmonic-fitting formula is $f(t, s)=A \cos [(2 \pi / T) t+s \lambda+\varphi]$, where $A, \varphi, T$ and $s$ are respectively the amplitude, phase, period and wavenumber of the QTDW. $T$ and $s$ are chosen according to the spectral peaks of QTDWs shown in Fig. 1. $t$ and $\lambda$ are respectively the universal time and longitude of each disturbance profile. In the $\mathrm{SH}(\mathrm{NH})$, the maximum QTDW amplitude often occurs in January (July), which coincides with previous research (Pancheva et al., 2004; Tunbridge et al., 2011). Therefore, only amplitudes in these months are statistical analyzed. Latitude-altitude variations of averaged amplitudes of different QTDWs from 2002 to 2011 in the NH (SH) are in qualitative agreement, so only results of the strongest QTDW mode of each hemisphere - $(2.13, \mathrm{~W} 3)$ of the SH and $(2.04, \mathrm{~W} 4)$ of the $\mathrm{NH}-$ are presented (Fig. 2). In each altitude and latitude band, there are 279 and 310 fitting results in the $\mathrm{SH}$ and $\mathrm{NH}$, respectively. Latitude-altitude distribution characteristics of QTDW amplitudes are basically consistent with previous research (McCormack et al., 2009; Tunbridge et al., 2011). The maximum amplitude of (2.13, $\mathrm{W} 3)$ and $(2.04, \mathrm{~W} 4)$ are $7.3 \mathrm{~K}$ at $85 \mathrm{~km}$ at $32^{\circ} \mathrm{S}$ and $3.3 \mathrm{~K}$ at $71 \mathrm{~km}$ at $36^{\circ} \mathrm{N}$, respectively. This suggests that QTDWs are a summertime phenomenon, and mainly exists in the middle and upper atmosphere at mid-high latitudes. The temporally averaged amplitude of (2.13, W3) in the SH is twice larger than $(2.04, \mathrm{~W} 4)$ in the $\mathrm{NH}$, and the peak altitude of $(2.13$, $\mathrm{W} 3)$ is $10 \mathrm{~km}$ higher than $(2.04, \mathrm{~W} 4)$. In addition, double al- titude peaks of both $(2.13, \mathrm{~W} 3)$ and $(2.04, \mathrm{~W} 4)$ are evident in summertime at certain latitudes. Amplitude peaks of (2.13, W3) occur at 60 and $83 \mathrm{~km}$ in the profile of $20^{\circ} \mathrm{S}$, and for $(2.04, \mathrm{~W} 4)$, double altitude peaks occur at about $35^{\circ} \mathrm{N}$ at 70 and $85 \mathrm{~km}$, respectively. Spatial distributions of QTDW amplitudes exhibit apparent interhemispheric differences. It may result either from topography differences (Salby, 1984) or from different structures of the background atmospheres in the middle and upper atmosphere at mid-high latitudes of both hemispheres.

\section{Short-term variations}

The concept of QTDW "lifetime" has been previously researched (Craig et al., 1980; Fritts et al., 1999; Pancheva et al., 2004; Malinga and Ruohoniemi, 2007). In a southern summer, the QTDW usually has one burst and last about 510 days (Fritts et al., 1999). Different from that, the QTDW often has 2-3 bursts during one northern summer, with durations of 9-10 or 14-17 days (Pancheva et al., 2004). However, these results are estimated morphologically from temporal variations of amplitudes. In this section, we introduce an explicit definition of lifetime, which is essential in research of short-term and interannual variations of QTDWs. Based on temporal variations of amplitudes, these definitions are described through a detailed case study of (2.13, W3), which had the most remarkable amplitude of all and happened at $32^{\circ} \mathrm{S}$ in the southern summer from December 2002 to February 2003. Characteristics of its phases and vertical wavelengths are presented as well. Moreover, horizontal winds during the same period are investigated using 

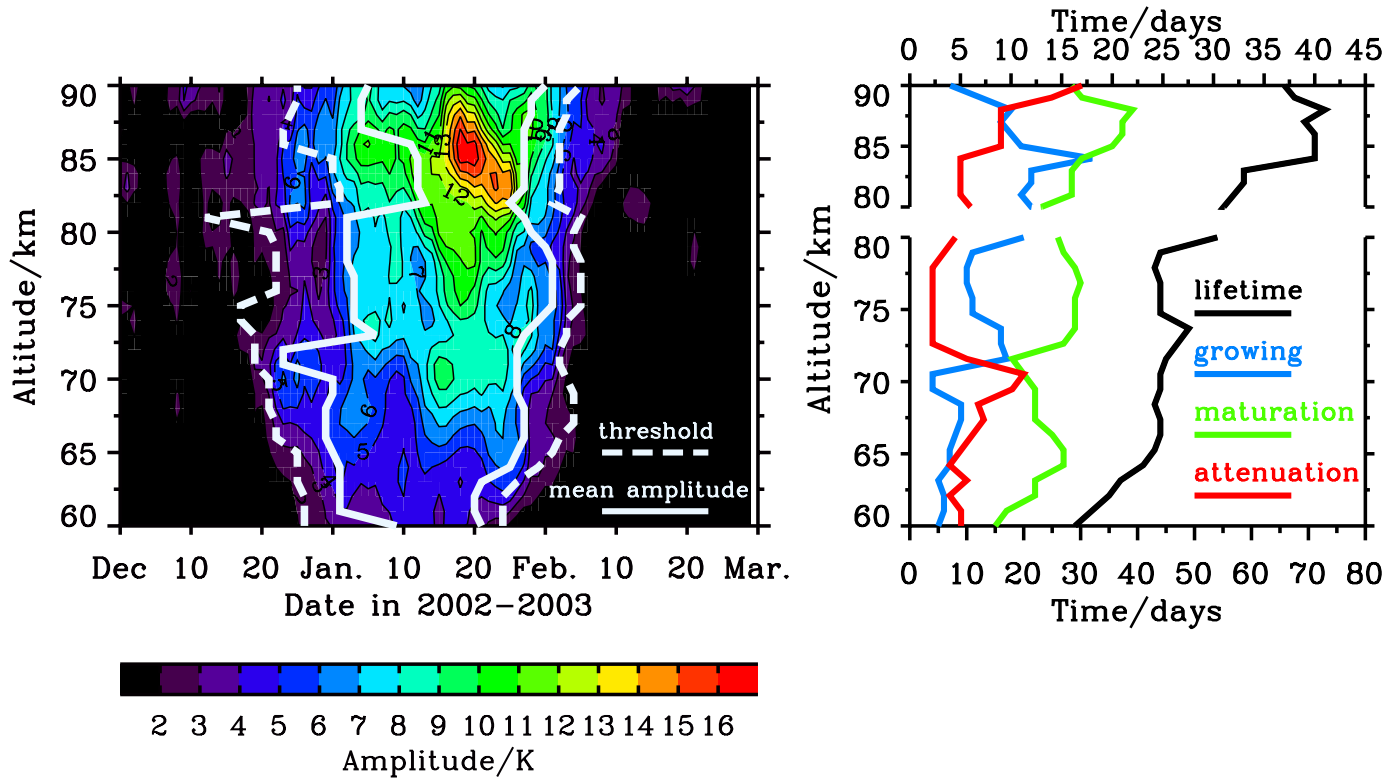

Fig. 3. Time-altitude variations of amplitudes of (2.13, W3) (left). Solid and dashed lines are profiles of mean amplitude and threshold, indicating time limit of maturation stage and lifetime. Altitude variations of durations of lifetime (black line), growing stage (blue line), maturation stage (green line) and attenuation stage (red line) are shown in the right panel. The bottom and upper x-axes in the right panel are for altitude ranges below and above $80 \mathrm{~km}$, respectively.

UARS/HRDI observations to show their impact on shortterm variations of these parameters.

\subsection{Amplitude}

Errors of SABER temperature does not exceed $\pm 1.5 \mathrm{~K}$ below $95 \mathrm{~km}$ and $\pm 4-5 \mathrm{~K}$ at $100 \mathrm{~km}$ for most latitudes and seasons (except for polar summer), while they can reach $\pm 3 \mathrm{~K}$ at $82 \mathrm{~km}$ and $\pm 8 \mathrm{~K}$ at $90 \mathrm{~km}$ for strong temperature inversion layers (García-Comas et al., 2008). Moreover, Gan et al. (2012) indicated that strong mesospheric temperature inversions often exist in winter for middle latitudes or in spring and autumn for mid-low latitudes. Therefore, according to the accuracy of SABER temperature measurements, we set thresholds of QTDWs as $2 \mathrm{~K}$ below $80 \mathrm{~km}$ and $5 \mathrm{~K}$ above $80 \mathrm{~km}$ in the altitude range $60-90 \mathrm{~km}$ during summertime (from December to February in the SH and from June to August in the NH). In each altitude, when the amplitude of the QTDW is greater than the threshold for four consecutive days, which is about twice the QTDW period, a QTDW event is considered to occur. Similarly, a QTDW event is considered to terminate if its amplitude is less than the threshold for four consecutive days. Accordingly, the first (last) day when the amplitude is greater than the threshold is defined as the starting (ending) day of the event, and the period between the starting day and the ending day is the lifetime of this event. Furthermore, for each altitude, average amplitudes during a lifetime are calculated, and from that we divide the lifetime into three stages. The growing stage is between the starting day and the day when amplitude reaches the average amplitude. The maturation stage is the days when amplitude is greater than the average amplitude. In this stage, amplitude increases first, and then begins to decrease after it reaches its peak. The last stage is attenuation stage, which is from the day when amplitude is less than the average amplitude to the ending day, and amplitude usually decreases monotonously in this stage. Figure 3 illustrates definitions of these stages and altitude variations of their durations.

At $32^{\circ} \mathrm{S}$ in the southern summer from December 2002 to February 2003, (2.13, W3) lasted from 15 December 2002 to 10 February 2003. In general, amplitudes of $(2.13, \mathrm{~W} 3)$ increased with altitude due to decreasing atmospheric density. It increased from $3-4 \mathrm{~K}$ at $60 \mathrm{~km}$ to about $17 \mathrm{~K}$ at $86 \mathrm{~km}$ on 18 January. Above $86 \mathrm{~km}$, amplitudes started to decrease because of dissipation. The duration of the lifetime as well as its three stages exhibited obvious altitude variations, which are depicted in the right panel of Fig. 3. The duration of the lifetime (black line) was 29-54 days, with 60-90 km average value about 40 days. It increased with altitude at both $60-80$ and $80-90 \mathrm{~km}$. The specious rapid reduction at $80 \mathrm{~km}$ is probably because of our definition of threshold. Comparing the durations of three stages, we find that the maturation (green line) stage, which lasted 13-30 days, was the longest stage of the lifetime. At $70-80 \mathrm{~km}$, it lasted about 30 days (about 14 periods) - 3/4 of the lifetime - which means that $(2.13, \mathrm{~W} 3)$ is very steady in this altitude range. Thus, we infer that the background atmosphere may be stable as well, and it is favorable to the upward propagation of wave energy. Between 70 and $85 \mathrm{~km}$, the duration of the growing stage is 

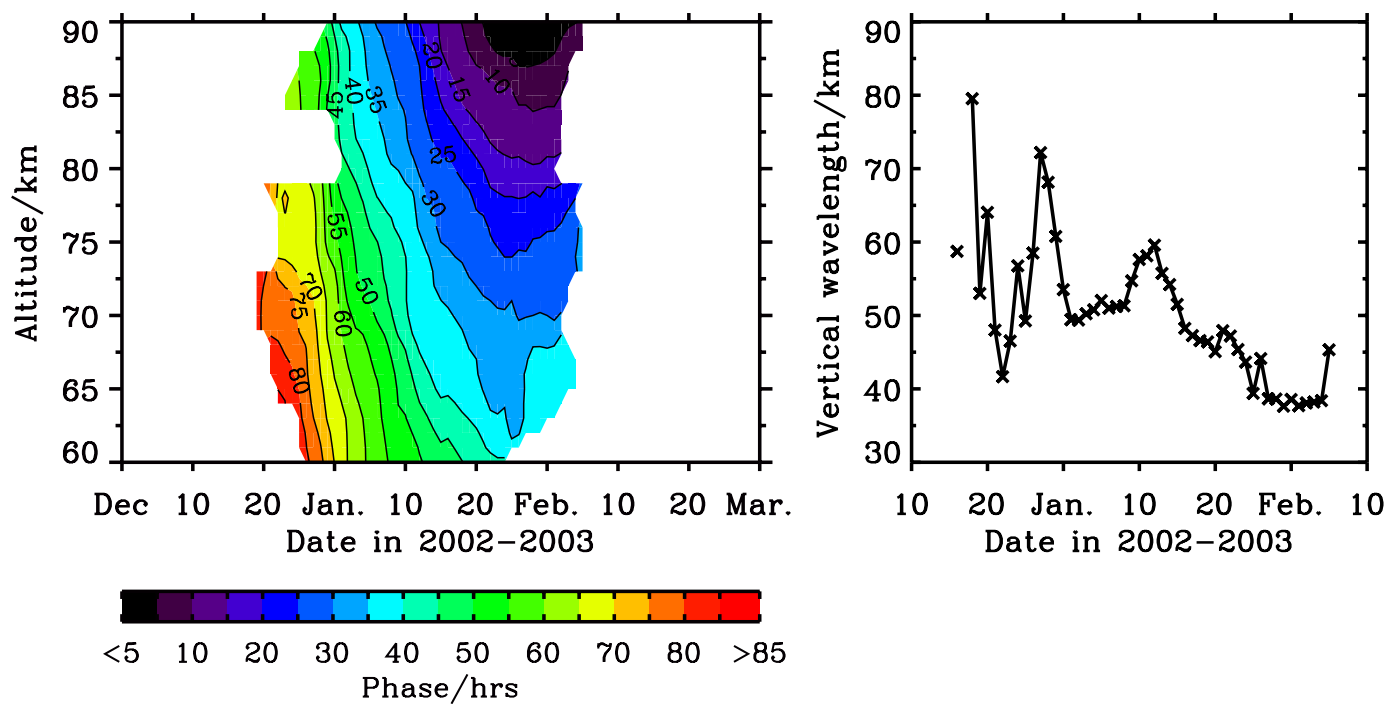

Fig. 4. Time-altitude variations of the phases of $(2.13, \mathrm{~W} 3)$ at $32^{\circ} \mathrm{S}$ (left) and day-to-day variations of its vertical wavelengths (right).

generally longer than that of the attenuation stage, which implies that $(2.13, \mathrm{~W} 3)$ may endure stronger dissipation at the end of summer.

\subsection{Phase and vertical wavelength}

Time-altitude variations of phase within the same event are contoured in the left panel of Fig. 4. The phase front decreased with altitude from 60 to $90 \mathrm{~km}$, indicating upward propagation of wave energy and a possible QTDW source region below $60 \mathrm{~km}$. Based on altitude variations of phases, vertical wavelengths are linearly fitted in a $10 \mathrm{~km}$ altitude window and $1 \mathrm{~km}$ running step in the same altitude range, and they manifested little altitude variations (not shown here). However, diurnally averaged vertical wavelengths exhibited evident day-to-day variations in different stages (Fig. 4, right panel). In the growing stage, from 22 to 29 December 2002, it increased sharply from 45.5 to $71.5 \mathrm{~km}$ in length and varied greatly, which indicated severe instability of $(2.13$, W3) at the beginning of its lifetime. Then it decreased essentially from 71.5 to $38.8 \mathrm{~km}$ in length during the maturation stage, from 30 December 2002 to 30 January 2003, which may imply a possible in-wind propagation of $(2.13, \mathrm{~W} 3)$. In the attenuation stage, from 31 January to 8 February 2003, vertical wavelengths basically remained unchanged at about $40 \mathrm{~km}$ before finally increasing to $45.3 \mathrm{~km}$. The distinct temporal variations of vertical wavelength during different stages of the lifetime indicate that different directions of horizontal winds may exist in different stages of the (2.13, W3) lifetime because the lengths of vertical wavelengths are most likely influenced by the relative directions of horizontal wind and the propagation of QTDWs.
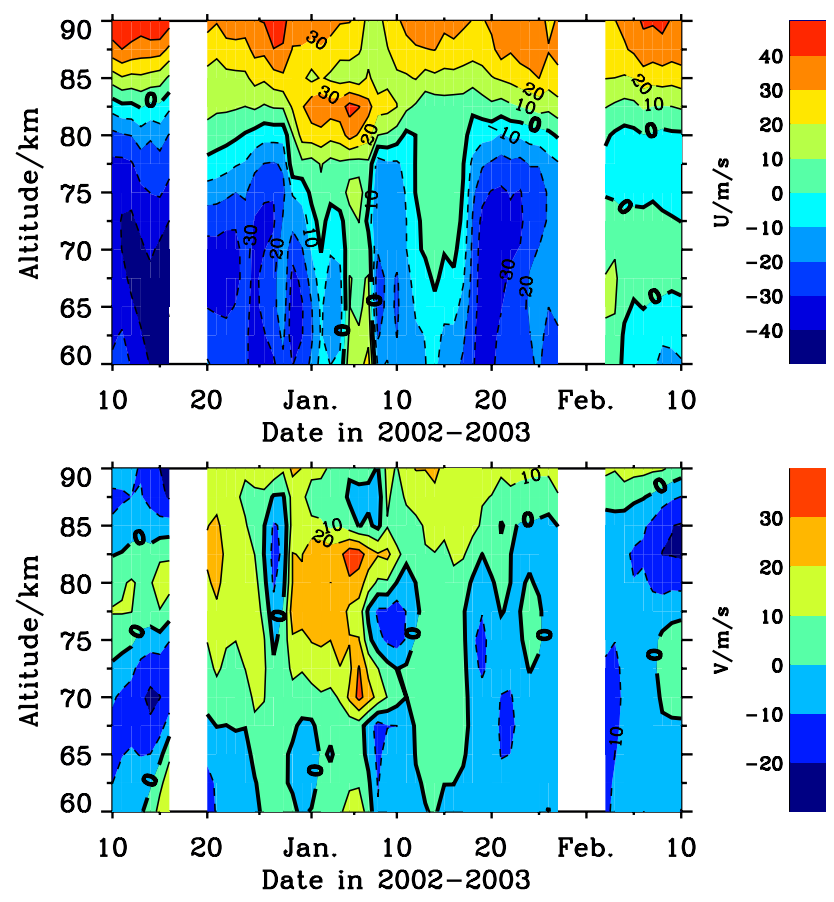

Fig. 5. Background zonal (upper, eastward positive) and meridional (bottom, northward positive) wind from UARS/HRDI observations. Blank denotes unavailable data.

\subsection{Background horizontal wind}

Background winds are able to impact propagation characteristics of atmospheric waves. In order to discover relationships between them further, we analyze the horizontal wind during the same period in the same latitude and altitude range. Time-altitude variations of background zonal and 
meridional wind are presented in the upper and lower panel of Fig. 5, respectively. Positive directions of wind are eastward and northward. Results presented in Fig. 5 are derived from zonal and meridional winds observed by UARS/HRDI in the $32^{\circ} \pm 2^{\circ} \mathrm{S}$ latitude band from December 2002 to February 2003. Level $2 \mathrm{~B}$ data are utilized here. HRDI local time coverage in the $32^{\circ} \pm 2^{\circ} \mathrm{S}$ latitude band shows that about 3$12 \mathrm{~h}$ local time is covered in each window, and more than $60 \%$ of intervals of the covered local time are greater than $10 \mathrm{~h}$ (figure not shown here).

There were two periods when zonal wind was easterly (westward) below $80 \mathrm{~km}$, while amplitudes of $(2.13$, W3) were only less than $6 \mathrm{~K}$ (Fig. 3, left panel). The former easterly occurred before 29 December 2002, and the latter one was from 17 to 27 January 2003. Above $85 \mathrm{~km}$, zonal wind reversed to a westerly direction and amplitudes of $(2.13$, W3) became larger, especially after January. Since 30 December 2002 until 9 January 2003, the westerly has extended gradually downward from 80 to $60 \mathrm{~km}$. Meanwhile, vertical wavelengths became longer (Fig. 4, right panel) and amplitudes in most altitudes increased evidently. Intervals of phase front became closer as well, indicating greater upward propagation speed of $(2.13, \mathrm{~W} 3)$ energy in westerly. It could be inferred that PWs are most likely to propagate upward against the wind. In the headwind condition, amplitudes and vertical wavelengths of PWs may increase and stretch, respectively. Downwind propagation of PWs might result in the decreasing of vertical wavelengths because of the absorption of wave by the background horizontal wind fields. In addition, a critical line of wind had moved downward from $82 \mathrm{~km}$ to about $70 \mathrm{~km}$ since 27 December 2002 until 2 January 2003. During this period, QTDWs below $80 \mathrm{~km}$ propagated against wind and could absorb energy from the background fields, and thus amplitude increased. After that, the critical line continued decreasing to below $65 \mathrm{~km}$ from 4 to 7 January, and, correspondingly, vertical wavelength became longer. Similarly, zonal wind reversed to westerly again during the period of 13-16 January. However, the speed and area of this westerly was respectively slower and smaller than the former reverse, so its influence over amplitude and vertical wavelength also seems less.

Although meridional wind was smaller than zonal wind, it is noticeable that the amplitude of $(2.13, \mathrm{~W} 3)$ decreased in the northerly region (southward) and increased in southerly (northward). For example, the amplitude seems less in the northerly region, $75-87 \mathrm{~km}$ in altitude from 27 to 29 December 2002 and $75-80 \mathrm{~km}$ in altitude from 10 to 12 January 2003, and greater in the southerly, from 60 to $90 \mathrm{~km}$ in altitude during the period of 13-19 January. Because QTDWs are likely to propagate in headwind condition, we can infer that $(2.13, \mathrm{~W} 3)$ is probably propagating southward. Nevertheless, the impact of meridional wind on the propagation characteristics of $(2.13, \mathrm{~W} 3)$ was less remarkable than zonal wind because of its relatively smaller wind speed. Analysis above indicates that horizontal wind plays an im- portant role in determining the propagation characteristics and parameter variations of QTDWs.

\subsection{Refractive index}

In order to study the vertical propagation characteristics of QTDWs, the squared refractive index $n^{2}$ is calculated. PWs can propagate upward freely when $n^{2}$ is positive. Otherwise, vertical propagations of PWs are blocked and their energy dissipates. In quasi-geostrophic atmosphere, $n^{2}$ can be written as (Andrews et al., 1987)

$n^{2}=\frac{\bar{q}_{\mathrm{y}}}{\bar{u}-C}-k^{2}-\frac{f^{2}}{4 N^{2} H^{2}}$

In this equation, $u$ is the zonally averaged zonal wind, $k=k_{0} / 2 \pi a \cos (\varphi)$ is the zonal wavenumber of wave $(a=$ $6.371 \times 10^{6} \mathrm{~m}$ is the radius of the earth, $\varphi$ is the latitude in radian, $k_{0}=-3$, is zonal wavenumber), $C=1 / k P$ is the phase speed of wave, and $P=2.13 \mathrm{~d}$ is the period of the QTDW. Positive $\bar{u}$ and $C$ denotes eastward. $f=2 \Omega \sin (\varphi)$ is the Coriolis parameters, where $\Omega=7.292 \times 10^{-5} \mathrm{~s}^{-1}$ is the rotational angular velocity of the earth. $N^{2}=\frac{g}{T}\left(\frac{\partial \bar{T}}{\partial z}+\frac{g}{c_{\mathrm{p}}}\right)$ is the squared buoyancy frequency, where $T$ is temperature in Kelvins, $z$ is altitude above sea level, $c_{\mathrm{p}}=1.005 \times$ $10^{3} \mathrm{~J} \mathrm{~kg}^{-1} \mathrm{k}^{-1}$ is constant pressure specific heat and $g=$ $9.8 \mathrm{~m} \mathrm{~s}^{-2}$ is gravitational acceleration. $H=-\frac{1}{\partial \ln \rho / \partial z}$ is the scale height of atmospheric density, $\rho$ is presented as the zonally averaged density of atmosphere, $\overline{q_{\mathrm{y}}}=\frac{2 \Omega \cos \varphi}{a}-\overline{u_{\mathrm{yy}}}-$ $\left(\frac{\bar{\rho} f^{2} \overline{u_{\mathrm{z}}}}{N^{2}}\right)_{\mathrm{z}}$ is the zonally averaged potential vorticity, and the second and third terms on the right side of the function are related to the barotropic and baroclinic instabilities of the atmosphere, respectively. $\overline{q_{\mathrm{y}}}$ is essential for atmospheric instability and will be generated in the easterly shear region (Charney and Stern, 1962; Plumb, 1983). Overbars in these functions denote the zonal average of the parameter beneath. Subscripts represent the direction of partial derivative. $y$ denotes the partial derivative along meridional direction with northward positive. The zonal average can be obtained by zonal averaging in a 6-day time window and 1 day step, in accord with the fitting of the QTDW. In the above calculations, densities and temperatures are from SABER Level 2A data, and both zonal and meridional winds are from HRDI Level 2B data.

Time-altitude variations of $n^{2}$ from December 2002 to February 2003 at $50-115 \mathrm{~km}$ at $32^{\circ} \mathrm{S}$ are presented in Fig. 6. $\overline{q_{\mathrm{y}}}=0$ is indicated by white lines. $n^{2}$ was positive in the westerly region from 80 to $100 \mathrm{~km}$, while mainly negative in the easterly region at 50-80 km from 12 December 2002 to the end of January 2003. It once again proves that zonal wind impacts the vertical propagation characteristics of QTDWs significantly (Charney and Drazin, 1961), and that the QTDW is able to propagate upward easier in the westerly region. Plumb (1983) pointed out that baroclinic instability may be a source of QTDWs, and $\overline{q_{\mathrm{y}}}<0$ is necessary for this 


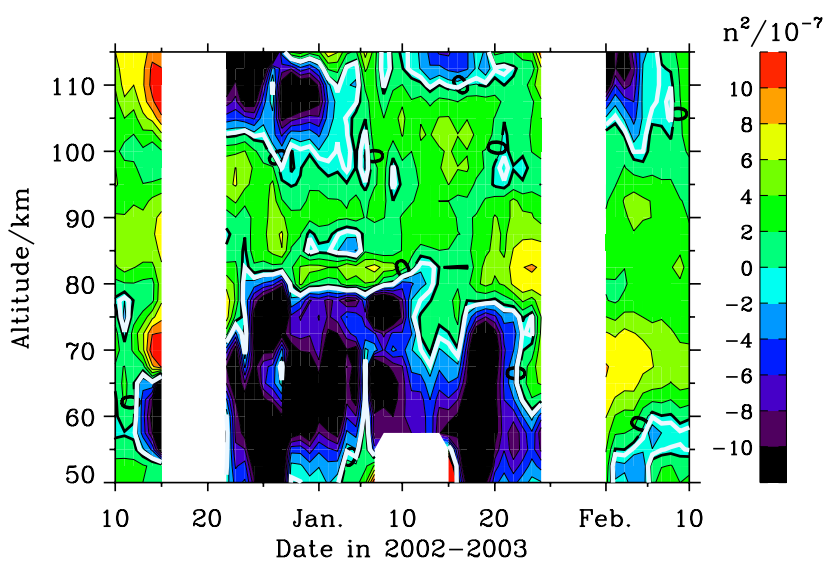

Fig. 6. Time-altitude cross section of the squared refractive index $n^{2}$ of $(2.13, \mathrm{~W} 3)$ at $32^{\circ} \mathrm{S}$. White solid lines denote that $\overline{q_{\mathrm{y}}}$ equals zero. The blank areas (15-22 December, 7-14 January and 2531 January) denote unavailable data.

instability. Therefore, QTDWs are most likely to be generated in regions where $\overline{q_{\mathrm{y}}}<0$. In our study, it corresponds to the easterly region below $80 \mathrm{~km}$. But this possible source region of QTDWs was superposed by the area of $n^{2}<0$. As a result, the generated QTDW may be trapped and its energy may dissipate. After that, the dissipated momentum would deposit itself into the background atmosphere and accelerate the easterlies. Therefore, the atmospheric instability was maintained and the QTDW was generated continuously. Nevertheless, in this region $n^{2}<0$, and the growing of the QTDW was hindered (Fig. 3, left panel). From 10 to 20 January, $n^{2}$ was positive in most altitudes from 80 to $90 \mathrm{~km}$, and the corresponding amplitude of the QTDW increased rapidly. An area where $n^{2}<0$ existed in $100-115 \mathrm{~km}$ from 22 December 2002 to 5 January 2003. This region might form a reflective layer of QTDWs and lead to the formation of standing waves between $80-100 \mathrm{~km}$, and the phase front did not propagate upward in this region correspondingly.

Time-altitude distributions of $n^{2}$ explain the variations of amplitude, phase and vertical wavelengths of (2.13, W3). It is confirmed that horizontal wind plays important roles in determining the propagation characteristics of the QTDWs: they are more likely to propagate upward in headwind conditions. Moreover, a reflection region of the QTDW is found to exist above $90 \mathrm{~km}$, which led the standing wave at $80-90 \mathrm{~km}$, where constant phases occur (Fig. 4, left panel).

\section{Interannual variations of QTDWs}

\subsection{Strength}

TIMED/SABER has been observing temperature of the middle and upper atmosphere continuously since 25 February 2002, which allows us to study the interannual variations of QTDW parameters from 2002 to 2011. At each latitude
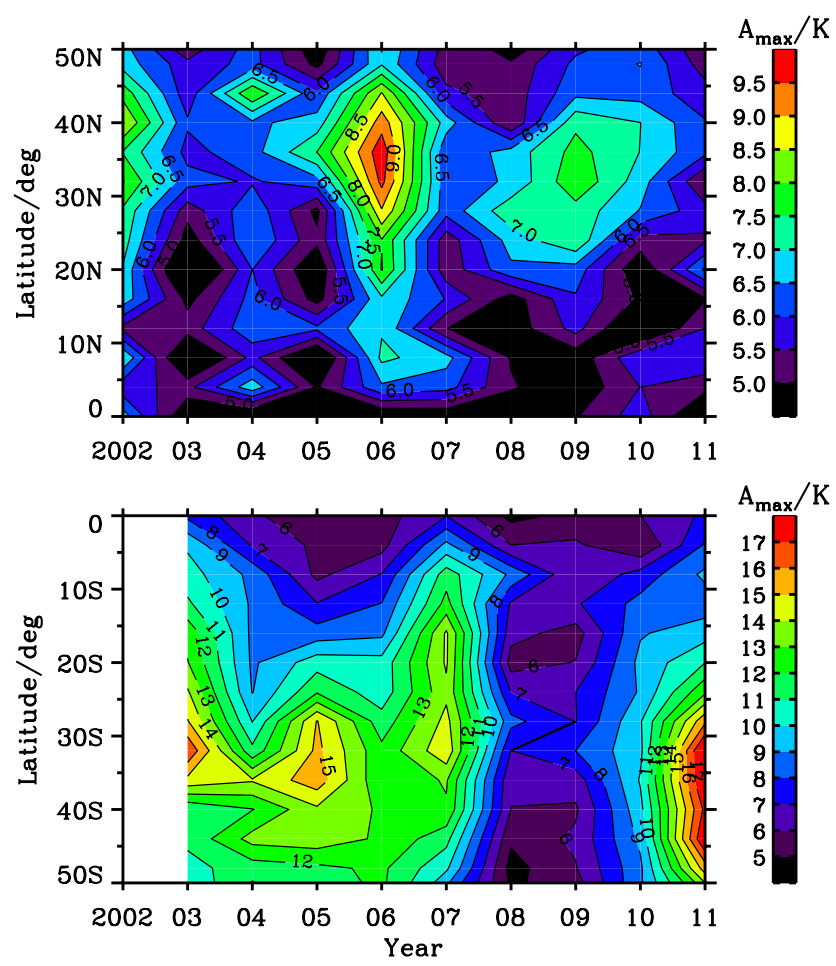

Fig. 7. Interannual variations of the strengths of $(2.04, \mathrm{~W} 4)$ in the $\mathrm{NH}$ (upper) and (2.13, W3) in the $\mathrm{SH}$ (bottom) in the mesosphere. Blank area denotes no observations.

band, we regard the annual maximum amplitude of QTDWs as their annual strengths, and their annual latitude variations are showed in Fig. 7. The upper and lower panels are for $(2.04, \mathrm{~W} 4)$ in the $\mathrm{NH}$ and $(2.13, \mathrm{~W} 3)$ in the $\mathrm{SH}$, respectively. Strengths of QTDWs exhibit remarkably interannual variations in all latitude bands of both hemispheres, except the latitude range between $10^{\circ} \mathrm{S}$ and $20^{\circ} \mathrm{N}$, where the strengths are relatively weaker. The maximum strength of $(2.04, \mathrm{~W} 4)$ in the $\mathrm{NH}$ is about $9.5 \mathrm{~K}$ in 2006 at $30-40^{\circ} \mathrm{N}$. The second largest strengths are about $7.5 \mathrm{~K}$ in 2002, 2004 and 2009 at mid-high latitudes of the $\mathrm{NH}$. In the $\mathrm{SH}$, the maximum strength of $(2.13, \mathrm{~W} 3)$ exists at $30-40^{\circ} \mathrm{S}$ in 2011 . Its strength is greater than $19 \mathrm{~K}$, which is about 2 times larger than the maximum strength of the $\mathrm{NH}$. In addition, three other peaks arise in 2003, 2005 and 2007 at $30^{\circ} \mathrm{S}$ with strengths of 14 $16 \mathrm{~K}$. Except 2009, strengths of both (2.04, W4) and (2.13, W3) exhibit a quasi-two-year variation period in general. In the $\mathrm{NH}$, strengths of $(2.04, \mathrm{~W} 4)$ are stronger in even years, and weaker in odd years, whereas in the $\mathrm{SH}$, strengths of $(2.13, \mathrm{~W} 3)$ are stronger in odd years, and weaker in even years. These features suggest that the influences of QBO in zonal wind can extend from lower latitudes to mid-high latitudes (Li et al., 2008).

QBO in the monthly zonal mean of the zonal wind at the equator (from $5^{\circ} \mathrm{S}$ to $5^{\circ} \mathrm{N}$ ) from 2002 to 2011 of the NCEP/NCAR reanalysis from $100 \mathrm{hPa}$ (near the equatorial 


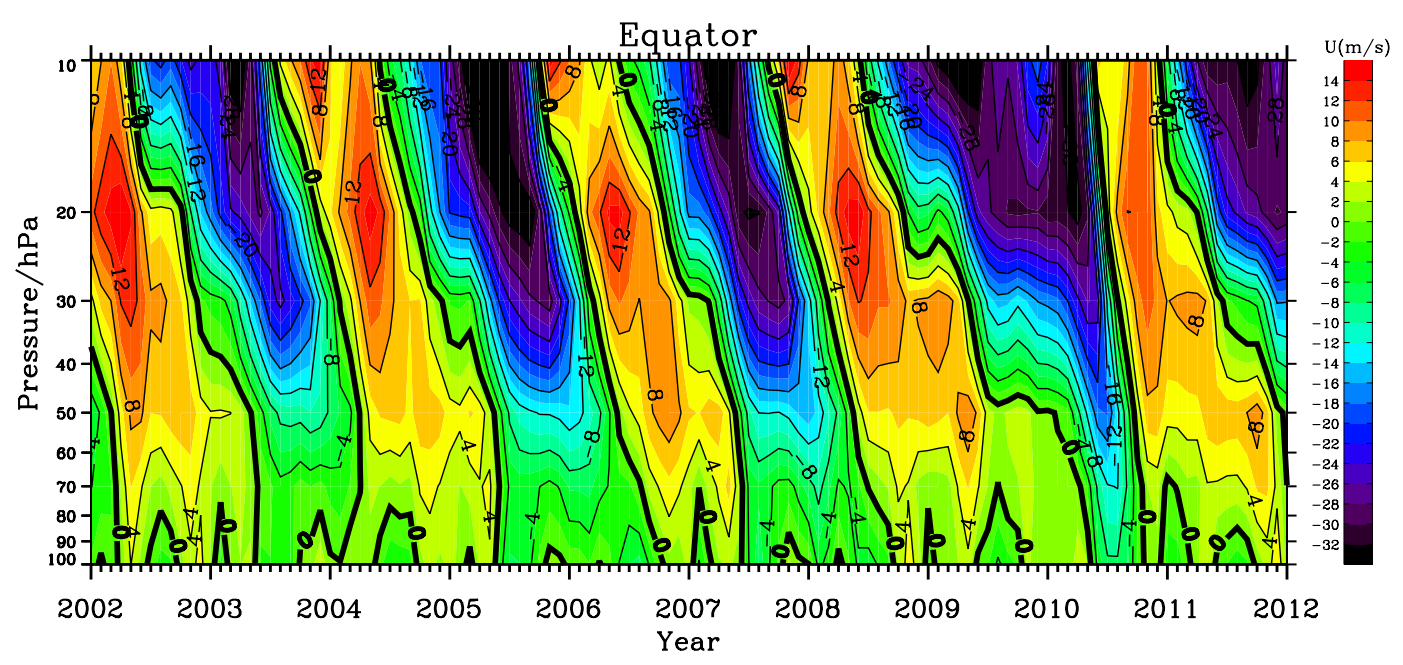

Fig. 8. Monthly zonal mean of the zonal wind at the equator (from $5^{\circ} \mathrm{S}$ to $5^{\circ} \mathrm{N}$ ) from 2002 to 2011 of the NCEP/NCAR reanalysis from 100 to $10 \mathrm{hPa}$, i.e. about $16-30 \mathrm{~km}$.

tropopause) to $10 \mathrm{hPa}-$ i.e. about $16-30 \mathrm{~km}-$ is shown in Fig. 8. We can see that, in the southern summer, the equatorial QBO is in the westerly (easterly) phase from 40 to $10 \mathrm{hPa}$ in most even (odd) years, and in the westerly (easterly) phase from 100 to $40 \mathrm{hPa}$ in most odd (even) years. It indicates that QTDW strength in the southern summer is usually stronger in the QBO's westerly phase from 100 to $40 \mathrm{hPa}$ and easterly phase from 40 to $100 \mathrm{hPa}$. While in the northern summer, the equatorial QBO is in easterly phase from 40 to $10 \mathrm{hPa}$ in most years, and in the easterly (westerly) phase from 100 to $40 \mathrm{hPa}$ in odd (even) years. As with that in the southern summer, QTDW strength in the northern summer tends to be stronger when QBO is in the westerly phase from 100 to $40 \mathrm{hPa}$, and the easterly phase from 40 to $10 \mathrm{hPa}$. Thus, we can infer that QBO plays a significant role in modulating QTDW interannual variations. QTDWs are easier to propagate upward in the equatorial QBO's westerly phase in the lower stratosphere and easterly phase in the middle stratosphere.

It is also shown in the observation results that the QTDW is stronger (weaker) in the solar maximum (minimum). The peak amplitude in 2009 may have resulted from the occurrence of SSW, but this theory is beyond the scope of this paper.

\subsection{Lifetime}

For each summertime from 2002 to 2011, we calculate the durations of lifetimes as well as the three stages of each $(2.13, \mathrm{~W} 3)$ in the SH and $(2.04, \mathrm{~W} 4)$ in the NH. In each latitude band during each summer, the durations at altitudes of the maximum QTDW amplitudes are taken as the annual durations, and their annual latitude distributions are presented in Fig. 9. Left and right columns are for (2.04, W4) in the $\mathrm{NH}$ and $(2.13, \mathrm{~W} 3)$ in the $\mathrm{SH}$, respectively. Four rows are for different stages of QTDWs: the first, second, third and fourth row represent durations of lifetime, growing stage, maturation stage and attenuation stage, respectively. All these durations exhibit evident interannual variations at all latitudes except the latitude range of $10^{\circ} \mathrm{S}-20^{\circ} \mathrm{N}$, where durations are relatively shorter. By comparing the interannual variations of all durations and strengths of (2.04, W4) (Fig. 7), it is obvious that interannual variations of growing stage and the strengths are most alike. Both of their peaks exist in 2002, 2004, 2006 and 2009. This means that strong QTDWs usually grow more slowly. Though interannual variation characteristics of other durations differ from the strength, they are identical to each other. They peak in 2003, 2005, 2007 and 2010, when QTDW strengths are relatively weaker. We also notice that the attenuation stage of $(2.04, \mathrm{~W} 4)$ is longer than the growing stage, and almost a half of the $(2.04$, W4) lifetime is the maturation stage, which means that $(2.04, \mathrm{~W} 4)$ grows fast and dissipates slowly. It may imply that background atmosphere in the $\mathrm{NH}$ is favorable to the generation and maintenance of QTDW. In the SH, interannual variations of durations are not in accordance with those of strengths completely, which is similar as in the NH. Furthermore, it can be seen that one half of the lifetime is the maturation stage, and growing stage is longer than the attenuation stage most of the time. This means that $(2.13, \mathrm{~W} 3)$ grows more slowly than it attenuates, which differs from $(2.04, \mathrm{~W} 4)$, suggesting that atmosphere in the southern summer is less favorable for the maintenance of QTDWs than the northern summer.

\subsection{Vertical wavelength}

For each summertime from 2002 to 2011 , we calculate the vertical wavelengths of $(2.13, \mathrm{~W} 3)$ in the $\mathrm{SH}$ and $(2.04$, W4) in the NH. In total, 4353 and 1503 results are obtained in each altitude on average. About $78.5 \%$ of $(2.13, \mathrm{~W} 3)$ 

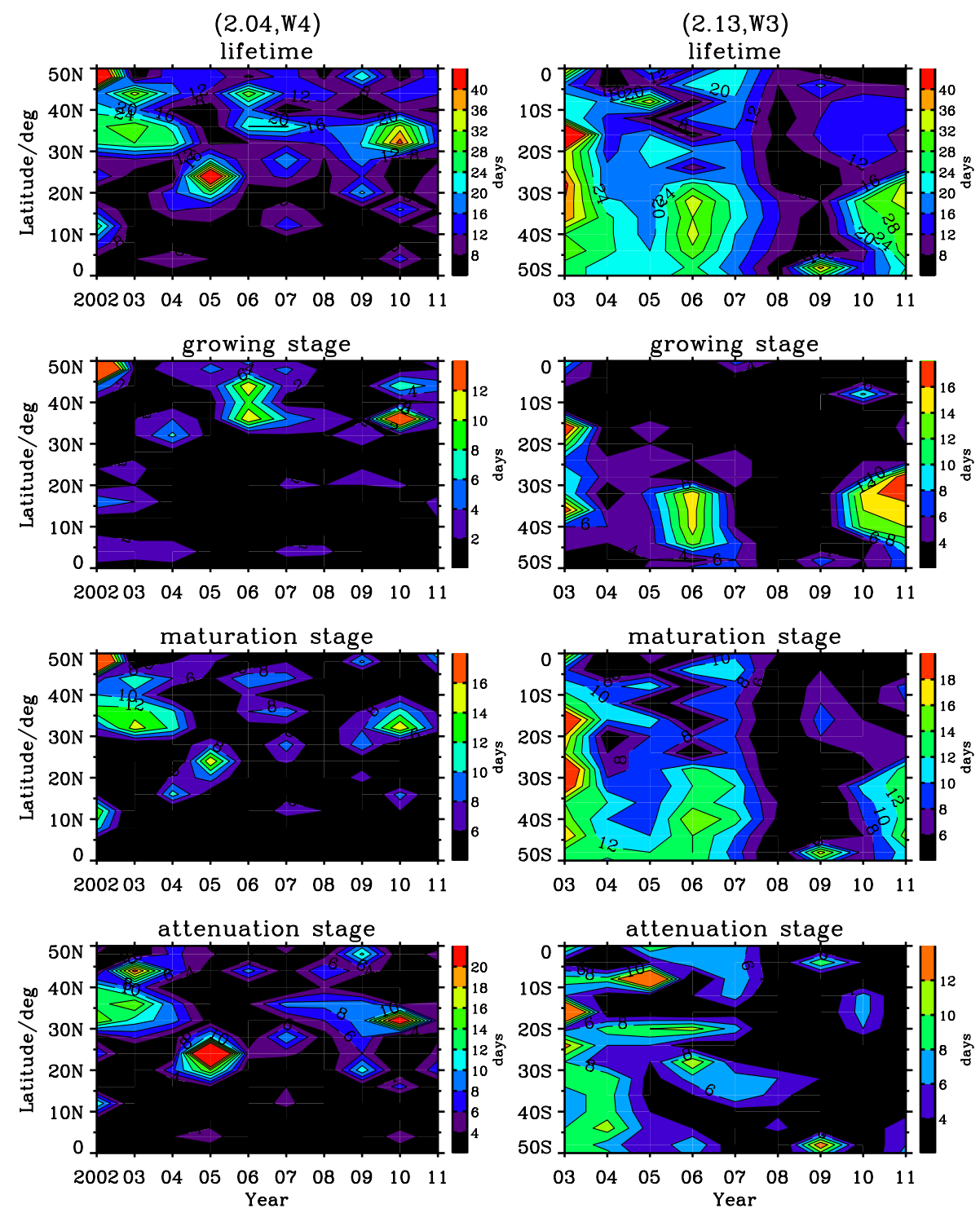

Fig. 9. Year-latitude cross sections of annual durations of lifetime (first row), growing stage (second row), maturation stage (third row) and attenuation stage (fourth row) for (2.04, W4) (left column) and (2.13, W3) (right column) at altitudes of their maximum amplitudes.

and $70.7 \%$ of $(2.04, \mathrm{~W} 4)$ vertical wavelengths are less than $100 \mathrm{~km}$ of which we perform statistical analysis. Following that, all these vertical wavelengths in the altitude range from 60 to $90 \mathrm{~km}$ in a summer are averaged at each latitude band and are taken as the annual mean vertical wavelengths. Annual latitude variations of these show hardly any regular interannual variation (not shown). In addition, the averaged vertical wavelengths of years 2002-2011 in each altitude are calculated at each latitude band; the latitudealtitude variations of them are shown in Fig. 10 The upper and lower panels of Fig. 10 are for results of (2.04, W4) and (2.13, W3), respectively. Obvious interhemispheric differences can be seen. For (2.04, W4) in the NH, latitude differences of vertical wavelengths are not evident. At most latitudes, vertical wavelengths decrease with altitude above $70 \mathrm{~km}$ and reach the minimum around $75 \mathrm{~km}$. A significant minimum appears at $75 \mathrm{~km}$ at $32^{\circ} \mathrm{N}$, where the maximum annual mean amplitude occurs. Above the minimum altitude they increase monotonously.However, the maximum vertical wavelength is longer than $60 \mathrm{~km}$ and exists between $45^{\circ} \mathrm{N}$ and $50^{\circ} \mathrm{N}$. Different from $(2.04, \mathrm{~W} 4)$, altitude variation characteristics of vertical wavelengths of $(2.13, \mathrm{~W} 3)$ present evident latitude differences. It basically decreases with altitude monotonously between $30-0^{\circ} \mathrm{S}$, where the lengths of vertical wavelengths vary between 36 and $60 \mathrm{~km}$. In $40-30^{\circ} \mathrm{S}$, a minimum (about $44 \mathrm{~km}$ ) exists near $80 \mathrm{~km}$, where the peak amplitude of $(2.13, \mathrm{~W} 3)$ just appears. In $50-40^{\circ} \mathrm{S}$, vertical wavelengths decrease with altitude below $72 \mathrm{~km}$ and increase 

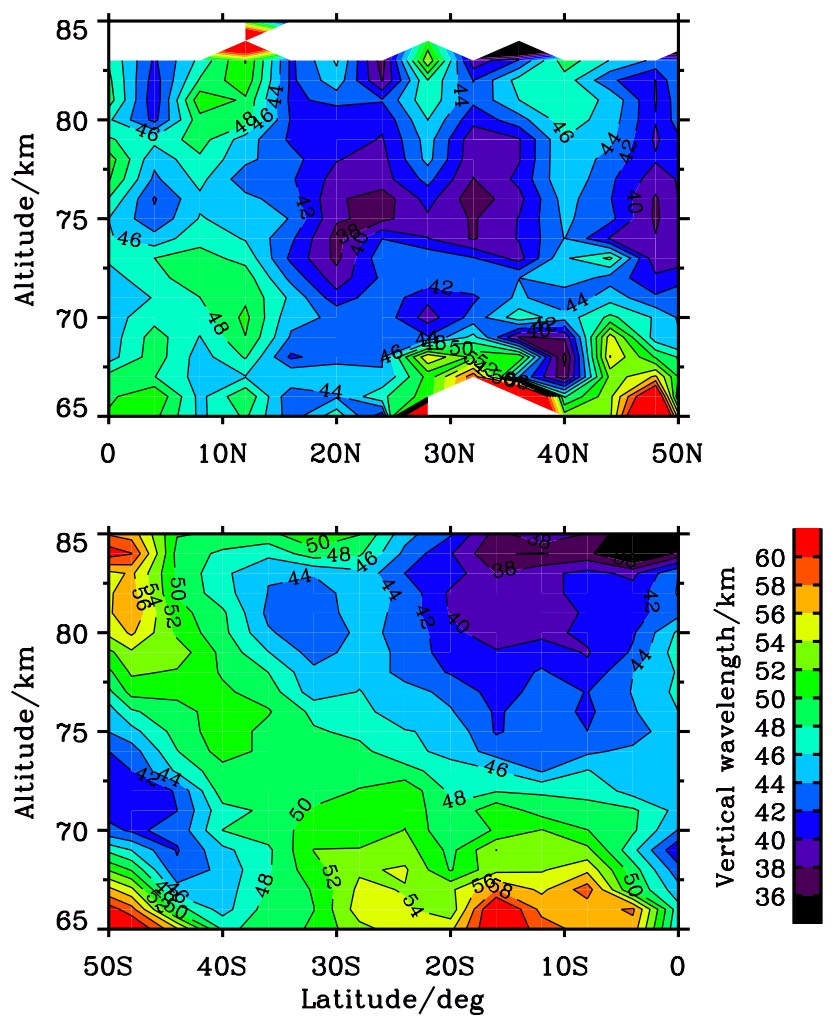

Fig. 10. Latitude-altitude cross sections of averaged vertical wavelengths for (2.04, W4) (upper) and (2.13, W3) (bottom).

above. The minimum vertical wavelengths are about 40 $42 \mathrm{~km}$. Different altitude variation characteristics of vertical wavelength may result from different background horizontal wind. However, latitude variations are also remarkable in each altitude. Below $70 \mathrm{~km}$, double maximums exceeding $60 \mathrm{~km}$ exist at 15 and $50^{\circ} \mathrm{S}$, respectively. At $70-75 \mathrm{~km}$, the vertical wavelengths decrease with latitude, and at 75$85 \mathrm{~km}$ it increases with latitude. The above descriptions imply that vertical wavelengths of $(2.04, \mathrm{~W} 4)$ and $(2.13, \mathrm{~W} 3)$ are $36-60 \mathrm{~km}$. Their altitude and latitude variations perform interhemispheric differences.

Furthermore, the occurrence possibilities of QTDWs at their amplitude peak altitude (Fig. 2) $-85 \mathrm{~km}$ for (2.13, W3) and $71 \mathrm{~km}$ for $(2.04, \mathrm{~W} 4)$ - are analyzed to get the length distributions of vertical wavelengths. Occurrence possibility is defined as the ratio of numbers of vertical wavelengths in each length range (the numerators) and the total number of vertical wavelengths less than $100 \mathrm{~km}$ (the denominator). Figure 11 shows the distributions of the occurrence possibilities of the (2.04, W4) (black line) and the (2.13, W3) (red line). They are in qualitative agreement, while peaks of them differ. For (2.04, W4), the peak occurrence possibility $-16.2 \%$ - is between 20 and $30 \mathrm{~km}$, and $54.3 \%$ of vertical wavelengths are between 10 and $40 \mathrm{~km}$. Of the $(2.13$, W3) vertical wavelengths, $25.0 \%$ of are between 30 and

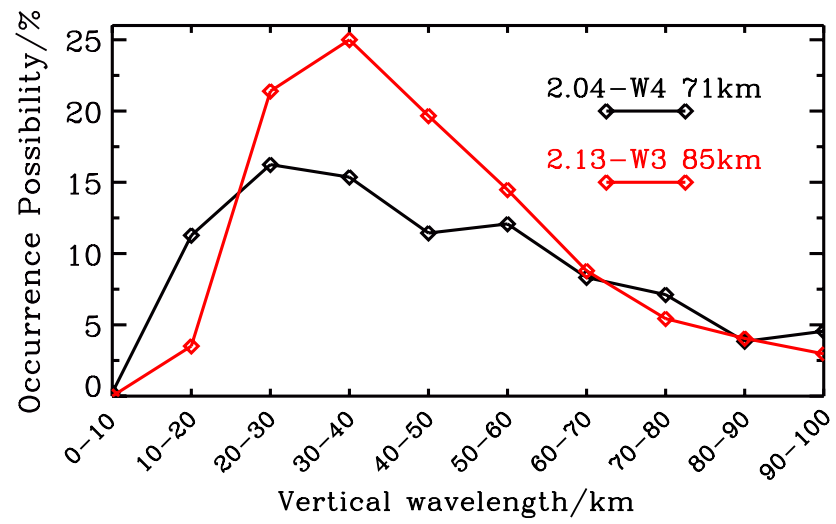

Fig. 11. Distributions of occurrence possibilities of vertical wavelengths of (2.13, W3) (red line) and (2.04, W4) (black line) in altitudes of their peak amplitudes.

$40 \mathrm{~km}$, and $65.4 \%$ of vertical wavelengths are between 30 and $50 \mathrm{~km}$. This indicates that vertical wavelengths of QTDWs are a little longer and more concentrated in the SH than that in the NH.

\section{Summary}

Quasi-two-day waves in the summertime of 2002-2011 from 60 to $90 \mathrm{~km}$ in altitude and from $52^{\circ} \mathrm{S}$ to $52^{\circ} \mathrm{N}$ in latitude are studied in this paper by using TIMED/SABER temperature data. The most obvious components of QTDWs in the SH and $\mathrm{NH}$ in normalized mean frequency-wavenumber spectra are $(2.13, \mathrm{~W} 3)$ and $(2.04, \mathrm{~W} 4)$, respectively. A case of the most remarkable QTDW event in SABER observations, the $(2.13, \mathrm{~W} 3)$ that occurred in the $\mathrm{SH}$ at $32^{\circ} \mathrm{S}$ in 2003 is studied in detail. For the first time, the lifetime of QTDWs is defined and is divided into stages of growing, maturation and attenuation according to the daily variations of amplitudes. It is shown that the duration of the growing stage equals that of the attenuation stage, and both of them are about 2 times shorter than the duration of the maturation stage. The phase front of this case decreases with altitude, indicating upward propagation of wave energy, which is also observed by Fritts et al. (1999). Thus, we can infer that a possible source region of QYDW may exist below $60 \mathrm{~km}$. In addition, vertical wavelength varies differently in different stages of lifetime. It varies rapidly in the growing stage, decreases in the maturation stage and remains stable in the attenuation stage.

Background zonal and meridional wind may play important roles in determining these short-term variations of QTDW parameters. Amplitudes increase obviously in easterly and northerly wind, which implies the westward and southward propagation of QTDWs. And vertical wavelength becomes longer (shorter) when a QTDW propagates against (with) the wind. Structures of refraction index and meridional gradient of potential vorticity can also explain the 
temporal and altitude variations of the QTDW partly. $n^{2}$ is positive in the westerly region where amplitude of the QTDW is larger, and mainly negative in the easterly region where amplitude is smaller. The amplitude of the QTDW increases with altitude above regions where meridional gradient of potential vorticity is negative, implying that baroclinic instability of the atmosphere may be a source of QTDWs, which was first proposed by Plumb (1983).

Basic characteristics of QTDW parameters during 20022011 are analyzed statistically and obvious interhemispheric differences are revealed. Peak altitude and latitude of (2.13, W3) in the SH are higher and lower than those of (2.04, W4) in the NH, respectively. Mean amplitudes in the SH are nearly twice larger than that in the NH. Although annual durations of lifetime and maturation stage of QTDWs in both hemispheres are almost equal, annual durations of attenuation stage in the $\mathrm{SH}$ is only half of that in the $\mathrm{NH}$, and durations of growing stage in the $\mathrm{SH}$ are a little longer than that in the $\mathrm{NH}$. Considering that amplitudes in the $\mathrm{SH}$ are larger, these durations imply that QTDWs decay faster in the SH and there may be more favorable background conditions in the NH for the generation and persistence of QTDWs. Daily mean vertical wavelengths in both hemispheres have quite close values, but latitude-altitude distributions of them differ in both hemispheres. Distributions of vertical wavelength occurrence probability for (2.13, W3) and (2.04, W4) are relatively similar, while peaks of them differ. $(2.13, \mathrm{~W} 3)$ has a slightly longer mean vertical wavelength and more concentrated distribution than $(2.04, \mathrm{~W} 4)$.

Strengths of QTDWs in both hemispheres show similar quasi-biennial variations, especially in mid-high latitudes. Furthermore, QTDWs are easier to propagate upward in the equatorial QBO's westerly phase in the lower stratosphere, and in the easterly phase in the middle stratosphere. It suggests the effect of the lower latitude zonal wind QBO on the PW can extend to mid-high latitudes. Solar activity can also modulate interannual variations of QTDW. Strengths of QTDWs appear to be greater (lesser) in the solar maximum (minimum).

Acknowledgements. This work was jointly supported by the National Basic Research Program of China (grant 2012CB825605), the National Natural Science Foundation of China (through grants 40825013, 41221003, 40974082 and 41174126), the Ocean Public Welfare Scientific Research Project of the State Oceanic Administration of the People's Republic of China (No. 201005017), a China Meteorological Administration grant (GYHY201106011), the Open Programs of the State Key Laboratory of Space Weather, and Fundamental Research Funds for the Central Universities.

Topical Editor C. Jacobi thanks two anonymous referees for their help in evaluating this paper.

\section{References}

Andrews, D. G., Holton, J. R., and Leovy, C. B.: Middle atmosphere dynamics, Academic, San Diego, Calif, 1987.

Babu, V. S., Kumar, K. K., John, S. R., Subrahmanyam, K. V., and Ramkumar, G.: Meteor radar observations of short-term variability of quasi 2 day waves and their interaction with tides and planetary waves in the mesosphere-lower thermosphere region over Thumba $\left(8.5^{\circ} \mathrm{N}, 77^{\circ} \mathrm{E}\right)$, J. Geophys. Res., 116, D16121, doi:10.1029/2010JD015390, 2011.

Burrage, M. D., Skinner, W. R., Gell, D. A., Hays, P. B., Marshall, A. R., Ortland, D. A., Manson, A. H., Franke, S. J., Fritts, D. C., Hoffman, P., McLandress, C., Niciejewski, R., Schmidlin, F. J., Shepherd, G. G., Singer, W., Tsuda, T., and Vincent, R. A.: Validation of mesosphere and lower thermosphere winds from the high resolution Doppler imager on UARS, J. Geophys. Res., 101, 10365-10392, doi:10.1029/95JD01700, 1996.

Charney, J. G. and Drazin, P. G.: Propagation of planetary-scale disturbances from the lower into the upper atmosphere, J. Geophys. Res., 66, 83-109, 1961.

Charney, J. G. and Stern, M. E.: On the stability of the internal baroclinic jets in a rotating atmosphere, J. Atmos. Sci., 19, 159-172, 1962.

Craig, R. L., Vincent, R. A., Fraser, G. J., and Smith, M. J.: The quasi 2-day wave in the Southern Hemisphere mesosphere, Nature, 287, 319-320, 1980.

Dou, X., Li, T., Xu, J., Liu, H.-L., Xue, X., Wang, S., Leblanc, T., McDermid, I. S., Hauchecorne, A., Kekhut, P., Bencherif, H., Heinselman, C., Steinbrecht, W., Mlynczak, M., and Russell III, J. M.: Seasonal oscillations of middle atmosphere temperature observed by Rayleigh lidars and theircomparisons with TIMED/SABER observations, J. Geophys. Res., 114, D20103, doi:10.1029/2008JD011654, 2009.

Dutta, G., Mohammad, S., Satyakumar, M., Reddy, Y. K., Vinay Kumar, P., Rao, P. V., and Ajay Kumar, M. C.: Quasi-two-day wave in the lower atmosphere over Hyderabad during summer of 2009, Ann. Geophys., 30, 57-66, doi:10.5194/angeo-30-572012, 2012.

Forbes, J. M. and Moudden, Y.: Quasi-two-day wave-tide interactions as revealed in satellite observations, J. Geophys. Res., 117, D12110, doi:10.1029/2011JD017114, 2012.

Forbes, J. M. and Zhang, X.: Quasi 2-day oscillation of the ionosphere: A statistical study, J. Atmos. Sol. Terr. Phys., 59, 10251034, 1997.

Fritts, D. C., Isler, J. R., Lieberman, R. S., Burrage, M. D., March, D. R., Nakamura, T., Tsuda, T., Vincent, R. A., and Reid, I. M.: Two-day wave structure and mean flow interactions observed by radar and High Resolution Doppler Imager, J. Geophys. Res., 104, 3953-3969, 1999.

Gan, Q., Zhang, S. D., and Yi, F.: TIMED/SABER observations of lower mesospheric inversion layers at low and middle latitudes, J. Geophys. Res., 117, D07109, doi:10.1029/2012JD017455, 2012.

Garcia, R. R., Lieberman, R., Russell III, J. M., and Mlynczak, M. G.: Large-scale waves in the mesosphere and lower thermosphere observed by SABER, J. Atmos. Sci., 62, 4384-4399, 2005.

García-Comas, M., López-Puertas, M., Marshall, B. T., Wintersteiner, P. P., Funke B., Bermejo-Pantaleón, D., Mertens, C. J., Remsberg, E. E., Gordley, L. L., Mlynczak, M. G., and Russell III, J. M.: Errors in Sounding of the Atmosphere using Broadband Emission Radiometry (SABER) kinetic temperature caused 
by non-local-thermodynamic-equilibrium model parameters, J. Geophys. Phys., 113, D24106, doi:10.1029/2008JD010105, 2008.

Harris, T. J.: A long-term study of the quasi-two-day wave in the middle atmosphere, J. Atmos. Terr. Phys., 56, 569-579, 1994.

Harris, T. J. and Vincent, R. A.: The quasi-two-day wave observed in the equatorial middle atmosphere, J. Geophys. Res., 96, 10481-10490, 1993.

Hays, P. B., Abreu, V. J., Dobbs, M. E., Gell, D. A., Grassl, H. J., and Skinner, W. R.,: The high-resolution doppler imager on the upper atmosphere research satellite, J. Geophys. Res., 98, 10713-10723, 1993.

He, W., Ho, S. P., Chen, H., Zhou, X., Hunt, D., and Kuo, Y.-H.: Assessment ofradiosonde temperature measurements in the upper troposphereand lower stratosphere using COSMIC radio occultation data, Geophys. Res. Lett., 36, L17807, doi:10.1029/2009GL038712, 2009.

Hecht, J. H., Walterscheid, R. L., Gelinas, L. J., Vincent, R. A., Reid, I. M., and Woithe, J. M.: Observations of the phaselocked 2 day wave over the Australian sector using mediumfrequency radar and airglow data, J. Geophys. Res., 115, D16115, doi:10.1029/2009JD013772, 2010.

Jacobi, Ch., Schminder, R., and Kürschner, D.: The quasi 2-day wave as seen from D1 LF wind measurements over Central Europe $\left(52^{\circ} \mathrm{N}, 15^{\circ} \mathrm{E}\right)$ at Collm, J. Atmos. Sol. Terr. Phys., 59, 1277-1287, 1997.

Jacobi, Ch., Schminder, R., and Kürschner, D.: Planetary wave activity obtained from long-period (2-18 days) variations of mesopause region winds over central Europe $\left(52^{\circ} \mathrm{N}, 15^{\circ} \mathrm{E}\right), \mathrm{J}$. Atmos. Sol. Terr. Phys., 60, 81-93, 1998.

John, S. R. and Kumar, K. K.: TIMED/SABER observations of global cold point mesopause variability at diurnal and planetary wave scales, J. Geophys. Res., 116, A06314, doi:10.1029/2010JA015945, 2011.

John, S. R. and Kumar, K. K.: TIMED/SABER observations of global gravity wave climatology and their interannual variability from stratosphere to mesosphere lower thermosphere, Clim. Dynam., 39, 1489-1505, 2012.

Kalnay, E., Kanamitsu, M., Kistler, R., Collins, W., Deaven, D., Gandin, L., Iredell, M., Saha, S., White, G., Woollen, J., Zhu, Y., Chelliah, M., Ebisuzaki, W., Higgins, W., Janowiak, J., Mo, K. C., Ropelewski, C., Wang, J., Leetmaa, A., Reynolds, R., Jenne, R., and Joseph, D.: The NCEP/NCAR 40-Year Reanalysis Project, B. Amer. Meteorol. Soc., 77, 437-471, 1996.

Kistler, R., Kalnay, E., Collins, W., Saha, S., White, G., Woollen, J., Chelliah, M., Ebisuzaki, W., Kanamitsu, M., Kousky, V., Dool, H., Jenne, R., and Fiorino, M.: The NCEP-NCAR 50-year reanalysis: monthly means CD-ROM and documentation, B. Amer. Meteorol. Soc., 82, 247-267, 2001.

Kulikov, M. Y.: Theoretical investigation of the influence of a quasi-2-day wave on nonlinear photochemical oscillations in the mesopause region, J. Geophys. Res., 112, D02305, doi:10.1029/2005JD006845, 2007.

Li, Z. J. and Ning, B. Q.: Planetary-scale wave observations over a low-latitude E region using simultaneous observations of VHF radar and ionosonde over Sanya $\left(18.34^{\circ} \mathrm{N}, 109.62^{\circ} \mathrm{E}\right)$, J. Geophys. Res., 115, A12325, doi:10.1029/2010JA015816, 2011.

Li, T., She, C. Y., Palo, S. E., Wu, Q., Liu, H. L., and Salby, M. L.: Coordinated lidar and TIMED observations of the quasi-two- day wave during August 2002-2004 and possible quasi-biennial oscillation influence, Adv. Space Res., 41, 1463-1471, 2008.

Lima, L. M., Alves, E. O., Batista, P. P., Clemesha, B. R., Medeiros, A. F., and Buriti, R. A.: Sudden stratospheric warming effects on the mesospheric tides and 2-day wave dynamics at $7^{\circ} \mathrm{S}, \mathrm{J}$. Atmos. Sol. Terr. Phys., 78-79, 99-107, 2012.

Lieberman, R. S.: Eliassen-Palm Fluxes of the 2-day wave, J. Atmos. Sci., 56, 2846-2861, 1999.

Limpasuvan, V. and Leovy, C. B.: Observation of the two-day wave near the southern summer stratopause, Geophys. Res. Lett., 22, 2385-2388, 1995.

Limpasuvan, V. and Wu, D. L.: Two-day observations of UARS Microwave Limb Sounder mesospheric water vapor and temperature, J. Geophys. Res., 108, 4307, doi:10.1029/2002JD002903, 2003.

Limpasuvan, V., Leovy, C. B., and Orsolini, Y. J.: Observed temperature two-day wave and its relatives near the stratopause, J. Atmos. Sci., 57, 1689-1701, 2000.

Limpasuvan, V., Wu, D. L., Schwartz, M. J., Waters, J. W., Wu, Q., and Killeen, T. L.: The two-day wave in EOS MLS temperature and wind measurements during 2004-2005 winter, Geophys. Res. Lett., 32, L17809, doi:10.1029/2005GL023396, 2005.

Malinga, S. B. and Ruohoniemi, J. M.: The quasi-two-day wave studied using the Northern Hemisphere SuperDARN HF radars, Ann. Geophys., 25, 1767-1778, doi:10.5194/angeo-25-17672007, 2007.

McCormack, J. P., Coy, L., and Hoppel, K. W.: Evolution of the quasi 2-day wave during January 2006, J. Geophys. Res., 114, D20115, doi:10.1029/2009JD012239, 2009.

McCormack, J. P., Eckermann, S. D., Hoppel, K. W., and Vincent, R. A.: Amplification of the quasi-two day wave through nonlinear interaction with the migrating diurnal tide, Geophys. Res. Lett., 37, L16810, doi:10.1029/2010GL043906, 2010.

Meek, C. E., Manson, A. H., Franke, S. J., Singer, W., Hoffmann, P., Clark, R. R., Tsuda, T., Nakamura, T., Tsutsumi, M., Hagan, M., Fritts, D. C., Isler, J., and Portnyagin, Y. I.: Global study of northern hemisphere quasi-2-day wave events in recent summers near $90 \mathrm{~km}$ altitude, J. Atmos. Terr. Phys., 58, 1401-1411, 1996.

Merzlyakov, E. G. and Pancheva, D. V.: The 1.5-5-day eastward waves in the upper stratosphere-mesosphere as observed by the Esrange meteor radar and the SABER instrument, J. Atmos. Sol. Terr. Phys., 69, 2102-2117, 2007.

Muller, H. G.: Long-period meteor wind oscillations, Phil. Trans. R. Soc. Lond., 271, 585-599, 1972.

Muller, H. G. and Nelson, L.: A travelling quasi 2-day wave in the meteor region, J. Atmos. Terr. Phys., 40, 761-766, doi:10.1016/0021-9169(78)90136-8, 1978.

Palo S. E., Roble R. G., and Hagan, M. E.: Middle atmosphere effects of the quasi-two-day wave determined from a General Circulation Model, Earth Planets Space, 51, 629-647, 1999.

Palo, S. E., Forbs, J. M., Zhang, X., Russell III, J. M., and Mlynczak, M. G.: An eastward propagating two-day wave: evidence for nonlinear planetary wave and tidal coupling in the mesosphere and lower thermosphere, Geophys. Res. Lett., 34, L07807, doi:10.1029/2006GL027728, 2007.

Pancheva, D., Mitchell, N. J., Manson, A. H., Meek, C. E., Jacobi, C., Portnyagin, Y., Merzlyakov, E., Hocking, W. K., MacDougall, J., Singer, W., Igarashi, K., Clark. R. R., Riggin. D. M., Franke, S. J., Kürschner, D., Fahrutdinova, A. N., Stepanov, A. 
M., Kashcheyev, B. L., Oleynikov, A. N., and Muller, H. G.: Variability of the quasi-2-day wave observed in the MLT region during the PSMOS campaign of June-August 1999, J. Atmos. Terr. Phys., 66, 539-565, 2004.

Pancheva, D., Mukhtarov, P., and Andonov, B.: Global structure, seasonal and interannual variability of the migrating semidiurnal tide seen in the SABER/TIMED temperatures (2002-2007), Ann. Geophys., 27, 687-703, doi:10.5194/angeo-27-687-2009, 2009.

Pedatella, N. M. and Forbes, J. M.: The quasi 2 day wave and spatial-temporal variability of the $\mathrm{OH}$ emission and ionosphere, J. Geophys. Res., 117, A01320, doi:10.1029/2011JA017186, 2012.

Plumb, R. A.: Baroclinic instability of the summer mesosphere: A Mechanism for the quasi-two-day wave?, J. Atmos. Sci., 40, 262-270, 1983.

Preusse, P., Ern, M., Eckermann, S. D., Warnerc, C. D., Picard, R. H., Knieling, P., Krebsbach, M., Russell III, J. M., Mlynczakg, M. G., Mertensg C. J., and Riese, M.: Tropopause to mesopause gravity waves in August: Measurement and modeling, J. Atmos. Sol. Terr. Phys., 68, 1730-1751, 2006.

Randel, W. J.: Observations of the 2-day wave NMC stratospheric analyses, J. Atmos. Sci., 51, 306-313, 1994.

Reber, C. A., Trevathan, C. E., McNeal, R. J., and Luther, M. R.: The upper atmosphere research satellite (UARS) mission, J. Geophys. Res., 96, 10643-10647, doi:10.1029/92JD02828, 1993.

Remsberg, E. E., Marshall, B. T., Garcia-Comas, M., Krueger, D., Lingenfelser, G. S., Martin-Torres, J., Mlynczak, M. G., Russell III, J. M., Smith, A. K., Zhao, Y., Brown, C., Gordley, L. L., Lopez-Gonzalez, M. J., Lopez-Puertas, M., She, C.-Y., Taylor, M. J., and Thompson, R. E.: Assessment of the quality of the Version 1.07 temperature-versus-pressure profiles of the middle atmosphere from TIMED/SABER, J. Geophys. Res., 113, D17101, doi:10.1029/2008JD010013, 2008.

Riggin, D. M., Lieberman, R. S., Vincent, R. A., Manson, A. H., Meek, C. E., Nakamura, T., Tsuda, T., and Portnyagin, Y. I.: The 2-day wave during the boreal summer of 1994, J. Geophys. Res., 109, D08110, doi:10.1029/2003JD004493, 2004.

Rodger, C. D. and Prata, A. J.: Evidence for a traveling two-day wave in the middle atmosphere, J. Geophys. Res., 86, 96619664, 1981.

Russell III, J. M., Mlynczak, M. G., Gordley, L. L., Tansock, J., and Esplin, R.: An overview of the SABER experiment and preliminary calibration results, Proc. SPIE Int. Soc. Opt. Eng., 3756, 277-288, 1999.

Salby, M. L.: The 2-day wave in the middle atmosphere: observations and theory, J. Geophys. Res., 86, 9654-9660, 1981.

Salby, M. L.: Sampling theory of asynoptic satellite observations. Part 1: space-time spectra, resolution and aliasing, J. Atmos. Sci., 39, 2577-2600, 1982a.

Salby, M. L.: Sampling theory of asynoptic satellite observations. Part 2: fast Fourier synoptic mapping, J. Atmos. Sci., 39, 26012614, $1982 b$.

Salby, M. L.: Survey of planetary-scale traveling waves: The state of theory and observations, Rev. Geophys., 22, 209-236, doi:10.1029/RG022i002p00209, 1984.
Salby, M. L. and Callaghan, P. F.: Interaction of the 2day wave with solar tides, J. Geophys. Res., 113, D14121, doi:10.1029/2006JD007892, 2008.

Tunbridge, V. M., Sandford, D. J., and Mitchell, N. J.: Zonal wave numbers of the summertime 2 day planetary wave observed in the mesosphere by EOS Aura Microwave Limb Sounder, J. Geophys. Res., 116, D11103, doi:10.1029/2010JD014567, 2011.

Vincent, R. A.: MF/HF radar measurements of the dynamics of the mesopause region-a review, J. Atmos. Terr. Phys., 46, 961-974, 1984.

Vincent, R. A.: Planetary and gravity waves in the mesosphere and lower thermosphere, Adv. Space Res., 10, 93-101, 1990.

Wang, R., Zhang, S. D., and Yi, F.: Radiosonde observations of high-latitude planetary waves in the lower atmosphere, Sci China Earth Sci., 53, 919-932, doi:10.1007/s11430-010-0069-0, 2010.

Wu, D. L., Hays, P. B., Skinner, W. R., Marshall, A. R., Burrage, M. D., Lieberman, R. S., and Ortland, D. A.: Observations of the quasi 2-day wave from the High Resolution Doppler Imagine on UARS, Geophys. Res. Lett., 20, 2853-2856, doi:10.1029/93GL03120, 1993.

Wu, D. L., Fishbein, E. F., Read, W. G., and Waters, J. W.: Excitation and evolution of the quasi-2-day wave observed in UARS/MLS temperature measurements, J. Atmos. Sci., 53, 728738, 1996.

Xu, J. Y., She, C. Y., Yuan, W., Mertens, C., Mlynczak, M., and Russell, J.: Comparison between the temperature measurements by TIMED/SABER and lidar in the midlatitude, J. Geophys.Res., 111, A10S09, doi:10.1029/2005JA011439, 2006.

Xu, J., Liu, H. -L., Yuan, W., Smith, A. K., Roble, R. G., Mertens, C. J., Russell III, J. M., and Mlynczak, M. G.: Mesopause structure from Thermosphere, Ionosphere, Mesosphere, Energetics, and Dynamics (TIMED)/Sounding of the Atmosphere Using Broadband Emission Radiometry (SABER) observations, J. Geophys. Res., 112, D09102, doi:10.1029/2006JD007711, 2007a.

Xu, J. Y., Smith, A. K., Yuan, W., Liu, H.-L., Wu Q., Mlynczak, M. G., and Russell III, J. M.: Global structure and long-term variations of zonal mean temperature observed by TIMED/SABER, J. Geophys. Res., 112, D24106, doi:10.1029/2007JD008546, $2007 b$.

Xu, J., Smith, A. K., Liu, H.-L., Yuan, W., Wu, Q., Jiang, G., Mlynczak, M. G., Russell III, J. M., and Franke, S. J.: Seasonal and quasi-biennial variations in the migrating diurnal tide observed by Thermosphere, Ionosphere, Mesosphere, Energeticsand Dynamics (TIMED), J. Geophys. Res., 114, D13107, doi:10.1029/2008JD011298, 2009.

Yang, S. and Zou, X.: Assessments of cloud liquid water contributions to GPS radio occultation refractivity using measurements from COSMIC and CloudSat, J. Geophys. Res., 117, D06219, doi:10.1029/2011JD016452, 2012.

Zhang, X. L., Forbes, J. M., Hagan, M. E., Russell III, J. M., Palo, S. E., Mertens, C. J., and Mlynczak, M. G.: Monthly tidal temperatures 20-120 km from TIMED/SABER, J. Geophys. Res., 111, A10S08, doi:10.1029/2005JA011504, 2006. 